\title{
Yttrium speciation in sulfate-rich hydrothermal ore-forming fluids
}

\author{
QIUSHI GUAN ${ }^{1,2}$, YUAN MEI ${ }^{2}$, BARBARA ETSCHMANN ${ }^{1}$, \\ MARION LOUVEL ${ }^{3}$, JOËL BRUGGER ${ }^{1}$ \\ ${ }^{1}$ School of Earth, Atmosphere and Environment, Monash \\ University, Clayton, VIC 3800, Australia, \\ qiushi.guan@monash.edu \\ ${ }^{2}$ CSIRO Mineral Resources, Kensington, WA 6151, \\ Australia, yuan.mei@csiro.au \\ ${ }^{3}$ Institute for Mineralogy, WWU Muenster, D-48149 \\ Germany
}

Rare earth elements (REE) have gained importance due to their widening industrial applications and their use as geochemical tracers. REE sulfate complexes are some of the most stable REE aqueous species in hydrothermal fluids, and may be responsible for REE transport and deposition in a wide variety of geological environments, ranging from sedimentary basins to magmatic hydrothermal settings. However, the thermodynamic properties of most REEsulfate complexes are derived from extrapolation of ambient temperature data, since direct information on REE-sulfate complexing under hydrothermal conditions is limited to a single study that derived formation constants for $\mathrm{Nd}, \mathrm{Sm}$ and $\mathrm{Er}$ in sulfate solutions to $250{ }^{\circ} \mathrm{C}$ (Migdisov and William-Jones, 2008).

In this study, we employ ab initio molecular dynamics (MD) simulations to calculate the speciation and thermodynamic properties of yttrium(III) in sulfate and chloride solutions at temperatures and pressures up to $500{ }^{\circ} \mathrm{C}$ and 800 bar. The MD results were complemented by in situ X-ray absorption spectroscopy (XAS) measurements. Our results show that yttrium(III) forms complexes with sulfate with both monodentate and bidentate structures over the investigated temperature range $\left(200{ }^{\circ} \mathrm{C}\right.$ to $\left.500{ }^{\circ} \mathrm{C}\right)$. In simulation boxes containing both chloride and sulfate, yttrium(III) bonds with less sulfate and forms mixed Y-Cl$\mathrm{SO}_{4}$ complexes. The thermodynamic properties for yttrium(III) sulfate complexes derived from MD enable a better modelling of REE transport in hydrothermal systems.

Migdisov, A. A., \& Williams-Jones, A. E. (2008). Geochimica et Cosmochimica Acta,72(21), 5291-5303. 